\section{Gastrointestinal Bleeding Due to Acute Pancreatitis}

P. Verger, M. Gruau, K. Dhunnoo, J. Blais

Centre Hospitalier Départemental Félix Guyon, Saint-Denis Cedex, La Réunion

Corresponding Author

P. Verger

Hépatogastroentérologie

C.H.D. Félix Guyon

97405 Saint-Denis

La Réunion

Fax: + 262-90-7731

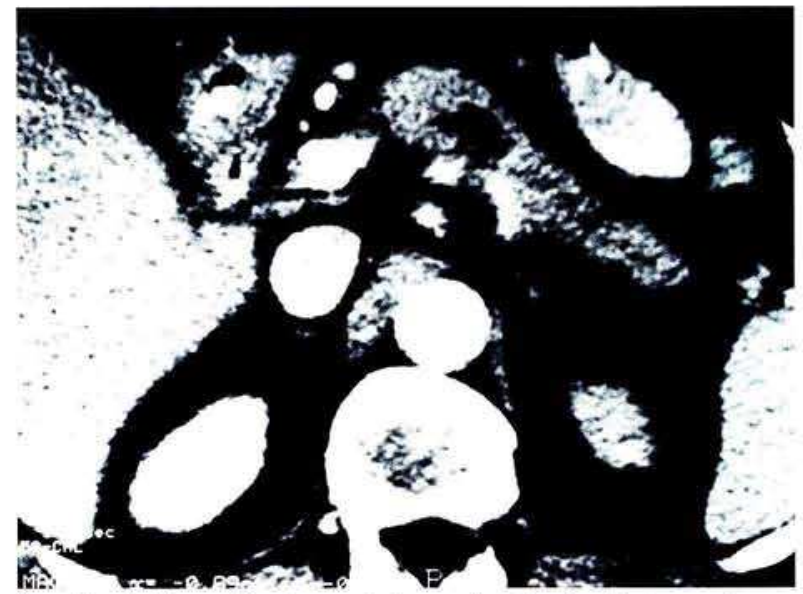

An alcoholic patient was twice admitted with hematemesis and melaena and severe deglobulisation. The pancreatic enzymes were subnormal. All the investigations were normal on the first occasion. A second gastric fibroscopy showed a hemorragic clot in the duodenal papilla. CT scan of the pancreas showed a hypodense area of $18 \times 10 \mathrm{~mm}$ in the isthmus of the pancreas. Celiomesenteric arteriography was normal, but pancreatography showed two stenoses in the isthmus and incomplete opacification of the tail. 